\title{
Dual Drug-Loaded Liposomes for Synergistic Efficacy in MCF-7 Breast Cancer Cells and Cancer Stem Cells
}

\author{
Hee-Bin Park ${ }^{1, *}$, Yun-Ji Kim ${ }^{1, *}$, Seong-Min Lee ${ }^{1, *}$, James S. Park ${ }^{2, * *}$ and Keun-Sik Kim ${ }^{1, \dagger, * *}$ \\ ${ }^{I}$ Department of Biomedical Laboratory Science, Konyang University, Daejeon 35365, Korea \\ ${ }^{2}$ NYU Langone Health, New York, NY 10016, USA
}

\begin{abstract}
Breast cancer stem cells (BCSCs) in breast cancer cells have self-renewal ability and differentiation potential. They are also resistant to drugs after chemotherapy. To overcome this resistance, we designed negatively charged 1,2dimyristoyl-sn-glycero-3-phosphoglycerol (DMPG)-based liposomes for drug delivery. These liposomes have enhanced the therapeutic effects of a range of antitumor therapies by increasing the cellular uptake and improving drug delivery to targets sites. In this study, we investigated whether DMPG-POPC liposomes, including the neutral lipid 1-palmitoyl-2oleoyl-sn-glycero-3-phosphocholin (POPC), can specifically bind to MCF-7 breast cancer cells and increase cellular uptake compared with that by CHOL-POPC liposomes. We also estimated the cytotoxicity of DMPG-POPC liposomes encapsulated with both metformin (Met) and sodium salicylate (Sod) against breast cancer cells and BCSCs compared with that of the free drugs. Our results demonstrated that these dual drug-encapsulated liposomes significantly enhanced the cytotoxic and anti-colony formation abilities compared with individual drug-encapsulated liposomes or free drugs in BCSCs. Overall, our results suggest that DMPG-POPC liposomes containing two drugs (Met + Sod) show promise for synergistic anti-cancer therapy of breast cancer by increasing drug delivery efficiency into breast cancer cells and BCSCs.
\end{abstract}

Key Words: Cancer stem cell, Combination chemotherapy, DMPG, Liposomes, Drug delivery, Metformin, Sodium salicylate

\section{INTRODUCTION}

Breast cancer is the most common type of cancer in women and the second most common cause of cancerrelated death in women (Zhang et al., 2014). Breast cancerrelated death is mainly due to the development of metastatic ability of the primary tumor (Minn et al., 2005). Considering the high mortality rate, it is critical to perceive the mechanisms underlying metastasis and verify new targets for breast cancer therapy. In the last few decades, despite various trials on cancer therapy, breast cancer has remained unconquered because of the invasive characteristics (Mukherjee et al., 2014; Kim et al., 2017a). The metastatic nature of breast cancer might be due to the existence of breast cancer stem cells (BCSCs; approximately $1 \%$ population) within a large population of breast cancer cells. Breast cancer stem cells (CSCs) are tumor cells that have the abilities of proliferation and self-renewal, and differentiation potential ( $\mathrm{Li}$ et al., 2008). In addition, several studies have proved that CSCs develop resistance to routine chemotherapy and radiotherapy, leading to cancer recurrence after treatment (Dean

Received: April 19, 2019 / Revised: May 13, 2019 / Accepted: May 22, 2019

* Graduate student, ${ }^{* *}$ Professor.

†Corresponding author: Keun-Sik Kim. Department of Biomedical Laboratory Science, Konyang University, Daejeon 35365, Korea.

Tel: +82-42-600-8434, Fax: +82-42-600-8408, e-mail: kskim11@konyang.ac.kr

(C) The Korean Society for Biomedical Laboratory Sciences. All rights reserved.

(c) This is an Open Access article distributed under the terms of the Creative Commons Attribution Non-Commercial License (http://creativecommons.org/licenses/by-nc/3.0/) which permits unrestricted non-commercial use, distribution, and reproduction in any medium, provided the original work is properly cited. 
et al., 2005; Gangemi et al., 2009; Kai et al., 2015; Lee, 2018).

Metformin (Met) is a drug that is generally prescribed for type 2 diabetics. Recently, metformin has attracted attention as a potentially beneficial drug for treating cancer. Several studies have demonstrated that patients with type 2 diabetes taking metformin have a considerably diminished risk of cancer and cancer-related death than those with diabetes not taking metformin (Evans et al., 2005; Bowker et al., 2006; Libby et al., 2009). In patients with breast cancer, especially those with diabetes, it has been implied that metformin improves sensitivity to chemotherapy compared with that in patients not taking metformin (Jiralerspong et al., 2009). Furthermore, recent studies have found that metformin promotes the induction of apoptosis and cell cycle arrest in several cancer cells (Dowling et al., 2007; Zakikhani et al., 2008; Alimova et al., 2009; Liu et al., 2009; Kim et al., 2017b), as well as prevents cellular transformation and CSC growth by inhibiting the associated inflammatory response (Hirsch et al., 2013) or suppressing CSC-specific gene expression (Bao et al., 2012).

Nonsteroidal anti-inflammatory drugs (NSAIDs) such as aspirin, sodium salicylate, and indomethacin — candidate anticancer drugs - are widely used to treat inflammation (Amann and Peskar, 2002). Aspirin and its natural deacetylated form sodium salicylate (Sod) promote anti-inflammatory activities by restraining the expression of diverse proinflammatory molecules, including prostaglandin (Amann and Peskar, 2002; Ulrich et al., 2006; Flossmann and Rothwell, 2007). These NSAIDs have also been revealed to possess tumor repressive activities by inducing apoptosis and cell cycle arrest in breast, lung, colon cancers, and leukemia (Bellosillo et al., 1998; Klampfer et al., 1999; Law et al., 2000; Dikshit et al., 2006). However, both metformin and sodium salicylate limit the sensitivity to anti-cancer therapies such as common chemotherapy and radiotherapy. Therefore, the development of breast cancer- and BCSC-targeting drug delivery systems is desirable to optimize anti-breast cancer and anti-BCSC therapies.

Nanocarriers are regarded as a useful platform for chemotherapeutic drug delivery, allowing therapeutic drugs to specifically target cancer cells by minimizing toxicity to normal cells (De Jong and Borm, 2008). Liposomes among various nanocarriers have been used as the most standard vehicle for targeted drug delivery. They consist of amphiphilic phospholipid bilayers, which can be encapsulated with both hydrophilic and hydrophobic drugs. Liposomes are also ideal nanocarriers for anti-breast cancer and anti-BCSCs therapeutics owing to their desirable characteristics such as biocompatibility, ease of surface modification, and prolonged blood circulation (Song et al., 2015; Jeong et al., 2016). However, it is still challenging to specifically deliver liposome-encapsulated drugs to cancer cells. This challenge has been overcome by designing a new class of lipids for liposomes. The new phenomenon of surface modification of liposomes can lead to the formulation of advanced drugdelivery systems using polyethylene glycol (PEG)-coated liposome modified with 1,2-dimyristoyl-sn-glycero-3-phosphoglycerol (DMPG) (Nag et al., 2013). According to recent studies, the improved activity of liposomal formulation is attributable to intra-liposomal activity by reaction with DMPG. The liposomal composition with DMPG and phosphatidylcholine (PC) lipids facilitate higher entrapment of a drug and flexibility in the selection of formulation, which delivers a higher proportion of drugs to the tumor (Zou et al., 1996). Thus, it is essential to use the DMPG-based liposomal delivery system that can deliver anticancer agents to breast cancer cells and BCSCs selectively. The aim of this study was to increase the therapeutic efficacy of a combination of metformin and sodium salicylate using the DMPG-POPC liposome delivery system.

\section{MATERIALS AND METHODS}

\section{Materials}

1,2-dimyristoyl-sn-glycero-3-phosphorylglycerol sodium salt (DMPG), 1,2-distearoyl-sn-glycero-3-phosphoethanolamine-N-[methoxy(po-lyethylene glycol)-2000 ammonium salt $\left(\mathrm{PEG}_{2000} \mathrm{PE}\right), 1$-palmitoyl-2-oleoyl-sn-glycero-3-phosphocholin (POPC), 1,2-dioleoyl-sn-glycero-3-phosphoethanolamine-N-[lissamine rhodamine B sulfonyl] (Rho-DOPE), and cholesterol (CHOL) were purchased from Avanti Polar Lipid, Inc. (Alabaster, AL, USA). Metformin and sodium salicylate were procured from Sigma-Aldrich (St. Louis, 
MO, USA). Human breast cancer cell line MCF-7 was purchased from the American Type Culture Collection (ATCC, Manassas, VA, USA).

\section{MCF-7 breast cancer cell culture}

MCF-7 cells were maintained in Eagle's minimum essential medium (EMEM) (ATCC) supplemented with $10 \%$ heat-inactivated fetal bovine serum (FBS) (GE healthcare, Chicago, IL, USA) and $1 \%$ penicillin and streptomycin (GE healthcare, Chicago, IL, USA). The cell lines were cultured in an incubator with $5 \% \mathrm{CO}_{2}$ at $37^{\circ} \mathrm{C}$.

\section{Breast cancer stem cells culture}

Mammosphere culture has been widely used to enrich CSCs (Ji et al., 2016). Therefore, for mammosphere culture in this study, single-cell suspensions of MCF-7 cells were seeded at 20,000 cells per well in six-well ultralow adherence plates (Corning, NY, USA) with DMEM/F-12 (Corning, NY, USA) containing $5 \mathrm{mg} / \mathrm{mL}$ insulin, 2\% B27 (Invitrogen Ltd., Paisley, Scotland), $20 \mathrm{ng} / \mathrm{mL}$ epidermal growth factor (EGF), and $20 \mathrm{ng} / \mathrm{mL}$ basic fibroblast growth factor (FGF) ( $2 \mathrm{~mL}$ per well). The cultures were passaged every seven days. When passaged, BCSCs were harvested and washed in $5 \mathrm{~mL}$ of DPBS. After centrifugation at 1,000 rpm for $3 \mathrm{~min}$, the harvested cells were gently suspended in trypsin and serum-free DMEM/F12 medium at a 1:1 ratio, and dispersed by pipetting with a 23-gauge needle. After confirming the dissociation of cells, the cells were pelleted and suspended in BCSCs culture medium at a concentration of 20,000 cells per well before placing in ultralow adherence six-well plates.

\section{Isolation of BCSCs with magnetic beads}

$\mathrm{CD} 44^{+} / \mathrm{CD} 24^{-}$are the expression biomarkers of interest in MCF-7-derived mammospheres. After continuous culture for two weeks, BCSCs were gathered for identification of MCF-7 BCSCs phenotype and purity. The gathered BCSCs were separated by pipetting with a 23-gauge needle and washed in DPBS two times. BCSCs enriched with CD44 ${ }^{+}$ CD24- were sorted from MCF-7 mammospheres using a MagCellect CD24/CD44 ${ }^{+}$breast Cancer Stem Cell Isolation Kit (R\&D System, Minneapolis, MN, USA) according to their protocol. Initially, CD $24^{+}$cells were labeled and re- moved magnetically. Thereafter, from the $\mathrm{CD}_{2} 4^{-}$population, $\mathrm{CD} 44^{+}$cells were sorted magnetically using a biotinylated human antibody and streptavidin-conjugated magnetic beads as a positive selection model. The efficiency of sorting was assessed by staining the recovered cells with fluorochromeconjugated anti-human $\mathrm{CD} 44^{+}$and $\mathrm{CD} 24^{-}$antibodies. Isolated $\mathrm{CD}^{2} 4^{+} / \mathrm{CD} 24^{-}$cells were later identified via FACS (ACEA Biosci-ences Inc, San Diego, CA, USA) analysis.

Preparation of liposomes loaded with metformin and sodium salicylate formulations (dual drug-loaded liposomes)

CHOL-POPC liposomes composed of PEG-DSPE, CHOL, and POPC (2:33:65, \% mol) and DMPG-POPC liposomes consisting of PEG-DSPE, DMPG, and POPC (2:33:65, $\%$ mol) were prepared. All lipids were mixed with chloroform -methanol mixture $(2: 1, \mathrm{v} / \mathrm{v})$. The chloroform-methanol mixture was evaporated with nitrogen gas, and then dried using a vacuum pump for $1 \mathrm{~h}$ to form a thin film of lipid. After drying, the lipid film was hydrated with $1 \mathrm{~mL}$ of Met and Sod solution for $1 \mathrm{~h}$ at $60^{\circ} \mathrm{C}$ in water bath. The solution was sonicated for $5 \mathrm{~min}$ at $60^{\circ} \mathrm{C}$. To prepare unilamellar vesicles from multilamellar vesicles, the liposome solution was extruded 10 times via Whatman nuclepore polycarbonate membrane filters (GE Healthcare, Chicago, IL, USA) of pore size ranging from 800 to $100 \mathrm{~nm}$ on an Avanti MiniExtruder (Avanti Polar Lipids, Alabaster, AL, USA). The uncapsulated drugs (Met or sodium salicylate) were separated from the liposome formulation by CL-4B gel-filtration. The total amount of encapsulated Met was determined by high performance liquid chromatography after disrupting the vesicles with Triton X-100. The drug content was analyzed at $235 \mathrm{~nm}$ using a liquid chromatograph Alliance 2690 (Waters). The column used was a C18 (60 ̊, $4 \mu \mathrm{m}$; Waters) and the mobile phase was PBS at $\mathrm{pH}$ 6, delivered at a flow rate of $0.8 \mathrm{mg} / \mathrm{mL}$.

\section{Observation of binding of CHOL-POPC and DMPG- POPC liposomes to cells}

The cellular binding affinity of CHOL-POPC and DMPGPOPC liposomes was evaluated in MCF-7 cells $\left(5 \times 10^{5}\right.$ cells/well) with an Axio Zeiss A1 Imager compound micro- 
scope (CarlZeiss, Oberkochen, Germany). The cells were grown in four-well-chamber slides (Nalgene Nunc International Corp., Naperville, IL, USA) for 24 h. Rhodaminelabeled CHOL-POPC and DMPG-POPC liposomes were added to MCF-7 cells, and then the treated cells were incubated for $5 \mathrm{~min}$ at $37^{\circ} \mathrm{C}$. After washing three times with DPBS, the cells were immediately investigated using an Axio Zeiss A1 Imager compound microscope $(\times 40)$.

\section{Cytotoxicity assay}

MCF-7 cells were seeded at a concentration of 40,000 cells per well in 96-well plates. After $24 \mathrm{~h}$, the medium was removed, and the cells were treated with Met (100, 200, and $300 \mathrm{mM}$ ), Sod (40, 80, and $160 \mathrm{mM}$ ), or DMPG-POPC liposome loaded with these drugs. The free drugs or drugloaded DMPG-POPC liposomes were removed after $4 \mathrm{~h}$ of incubation at $37^{\circ} \mathrm{C}$, and then $100 \mu \mathrm{L}$ of serum-containing medium was added to each well. After another $24 \mathrm{~h}, 10 \mu \mathrm{L}$ of EZ-CyTox reagent (Daeil Lab Service, Seoul, South Korea) was added to each well and incubated for $1 \mathrm{~h}$ at $37^{\circ} \mathrm{C}$. The absorbance of the samples was measured at $450 \mathrm{~nm}$ using an ELISA microplate reader. Mean optical density at each drug concentration was calculated after discarding the highest and lowest values. The anti-tumor effects of respective drugs (Met or Sod) for each MCF-7 cell line were shown in terms of inhibitory concentration at $25 \%\left(\mathrm{IC}_{25}\right)$ or $50 \%$ $\left(\mathrm{IC}_{50}\right)$ for Met or Sod, which was determined by plotting the graph of percentage of cell growth inhibition (Y-axis) versus drug concentration (X-axis). $\mathrm{IC}_{25}$ and $\mathrm{IC}_{50}$ values were expressed as mean and standard errors (SE). The assays were repeated more than three times.

To determine the combination effects of Met and Sod in BCSCs, the isolated BCSCs were seeded in 96-well ultralow adherence plates (Corning, NY, USA) (5,000 cells/well) and incubated for $2 \mathrm{~h}$. The cells were treated with doxorubicin (Dox), Met, Sod, or a combination of free drugs [Met and Sod] and drug-loaded DMPG-POPC [Met and Sod] (Combination), compared with $\mathrm{CD} 44^{-/ \mathrm{low}} / \mathrm{CD} 24^{+}$population, and then analyzed using the WST-1 method after $48 \mathrm{~h}$. The absorbance of the samples was measured at $450 \mathrm{~nm}$ using an ELISA microplate reader.

\section{Colony formation assay}

Breast cancer stem cells were seeded in a six-well plate at 5,000 cells/well concentration. After $2 \mathrm{~h}$, the cells were treated with control, Lipo-Empty, free drugs (Dox, Met, Sod, and Met+Sod), and drug-loaded CHOL-POPC and DMPGPOPC liposomes (Dox, Met, Sod, and Met+Sod) to each well. After incubation for 14 days, the visible colonies were stained with $1 \mathrm{~mL}$ of crystal violet for $10 \mathrm{~min}$, and then washed three times with DPBS after each step. After drying, the colonies were observed and scored under an inverted microscope. The percentage of colony formation was calculated using the following equation:

$\begin{gathered}\text { Colony formation } \\ (\% \text { of control })\end{gathered}=\frac{\text { Number of colonies after treatment }}{\text { Number of colonies of control }} \times 100$

\section{Statistical analysis}

The experiment results are represented as mean \pm SD (standard deviation). Statistical significance was determined by two-tailed Student's $t$-test. The results with $P<0.05$ or $P<0.01$ were regarded statistically significant.

\section{RESULTS}

\section{Characterization of breast cancer stem cells}

Breast cancer stem cells originated from MCF-7 cells grew as non-adherent mammospheres. The mammospheres of BCSCs were formed after culture for one week, and their diameter increased for three weeks (Fig. 1A). To compare the phenotypes of MCF-7 cells and BCSCs, BCSCs were isolated, and then mixed with anti-CD44-PE and anti-CD24APC depending on the property of BCSCs, including CD44 ${ }^{+}$ /CD24\%/low surface markers. The proportion of $\mathrm{CD} 44^{+}$ $\mathrm{CD} 24$ /low cells in BCSCs at 7, 14, and 21 days after culture and that in MCF-7 cells was 20.38\%, 40.34\%, 21.51\%, and $6.51 \%$, respectively, determined by flow cytometry (Fig. 1B). Compared with MCF-7 cells, BCSCs separated from MCF-7 cells inhibited normal CSC-like nature. Therefore, these results verified the successful isolation of BCSCs from MCF-7 cells. 
A

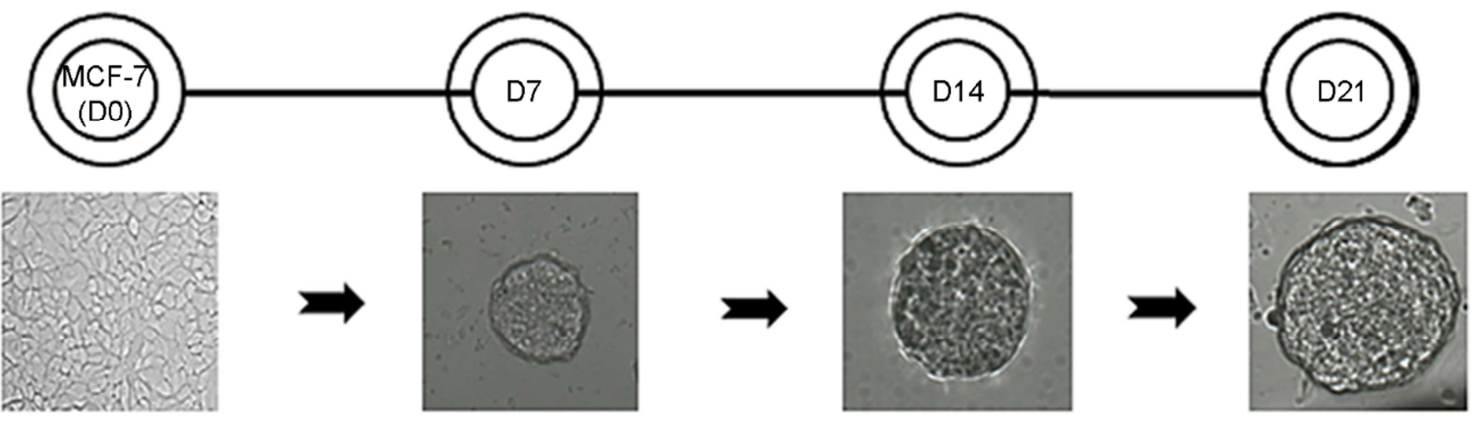

B
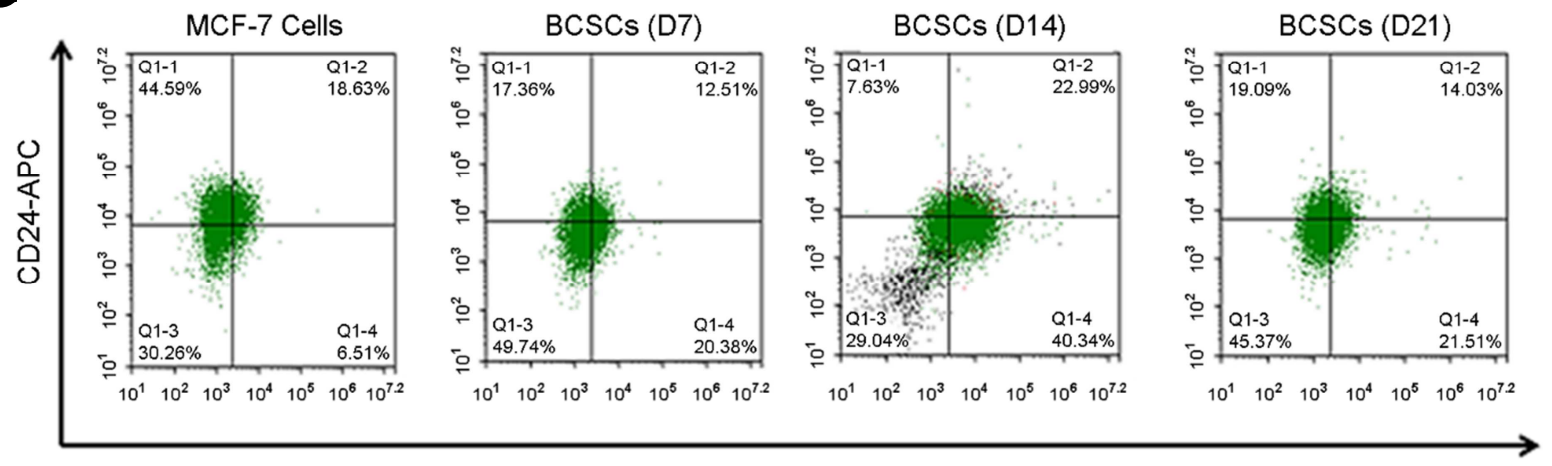

CD44-PE

Fig. 1. Isolation and characterization of breast cancer stem cells (BCSCs). (A) Morphology of BCSCs from MCF-7 cells at 7, 14 and 21 days of culture, observed using the microscope. MCF-7 cells were capable of forming BCSCs of about $50 \mathrm{~mm}$ in diameter under BCSCs culture condition for 1 week. (B) BCSCs and MCF-7 cells were analyzed using fluorescence activated cell sorting (FACS) and showed cell surface proteins. BCSCs at 14 days showed higher levels of CD44 ${ }^{+}$CD24/low populations than MCF-7 cells or BCSCs at 7 and 21 days cells.

A
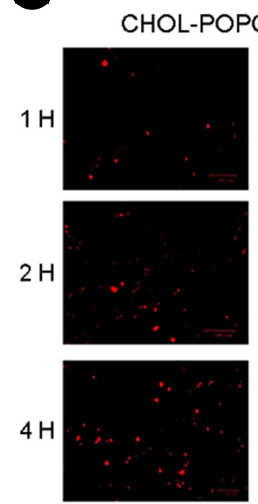

Rhodamine
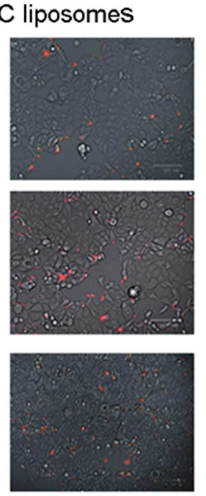

Merge
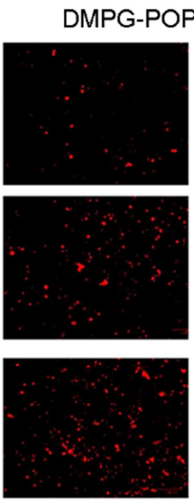

Rhodamine
B
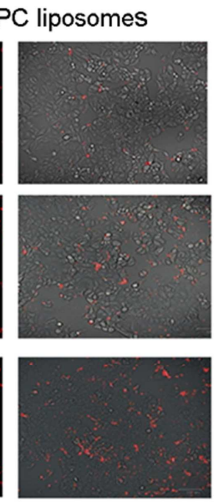

Merge

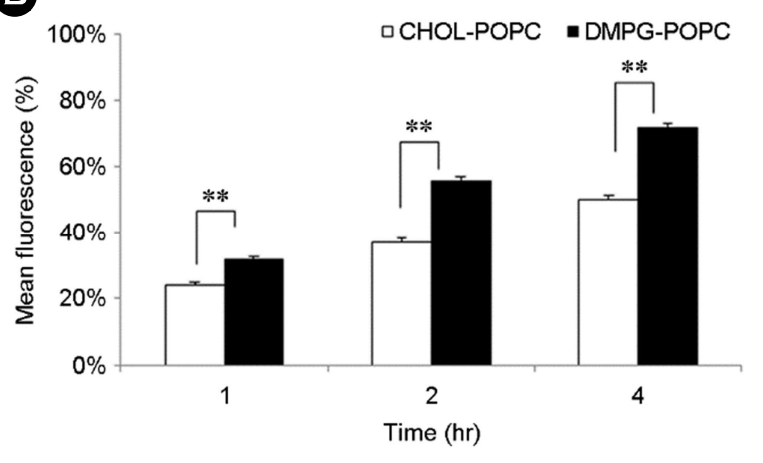

Fig. 2. Cell uptake of CHOL-POPC or DMPG-POPC liposomes to MCF-7 breast cancer cells. (A) MCF-7 cells treated with CHOLPOPC and DMPG-POPC liposomes were incubated in time dependent (1, 2, and $4 \mathrm{hrs})$. MCF-7 cells were washed with DPBS buffer three times and were observed using fluorescence microscope. The treated concentration of rhodamine labeled liposome was fixed at $20 \mu \mathrm{g}$ in all experiments and showed red color in each cells. (B) Red fluorescence of each rhodamine-labeled liposome on MCF-7 cells evaluated using Tail $^{\circledR}$ image based cytometer. Error bars represent standard deviation of three independent experiments $(\mathrm{n}=3, * * P<0.01$ when compared to DMPG-POPC with CHOL-POPC liposome). 


\section{Binding of CHOL-POPC or DMPG-POPC liposomes to}

\section{MCF-7 breast cancer cells}

To compare cellular binding of CHOL-POPC and DMPGPOPC liposomes, MCF-7 cells were made to take up CHOLPOPC and DMPG-POPC liposomes for different intervals (1, 2, and 4 h). As shown in Fig. 2B, cell surface binding of DMPG-POPC liposome was $32 \%, 57 \%$, and $71 \%$ on MCF7 cells at 1,2, and $4 \mathrm{~h}$. Whereas, CHOL-POPC liposome bound to MCF-7 cells showed relatively low uptake of $24 \%$, $37 \%$, and $50 \%$ at 1,2 , and $4 \mathrm{~h}$, respectively. The cell binding of these DMPC-POPC liposomes increases at least $20 \%$ $(P<0.01)$ on the surface of MCF-7 cells at $4 \mathrm{~h}$ when compared to CHOL-POPC liposomes. Fluorescence images in Fig. 2A verified these results. Furthermore, DMPG-POPC liposomes bound rapidly to the cells at $1 \sim 4 \mathrm{~h}$, and a strong signal was observed by fluorescence microscopy. These results demonstrated that DMPG-POPC liposome nanoparticles can cross the cell membrane barrier better than CHOLPOPC liposomes. Hence, we used DMPG-POPC liposomes to validate the antitumor effect of drug-encapsulated liposomes in comparison with that of free drugs on breast cancer
(A)

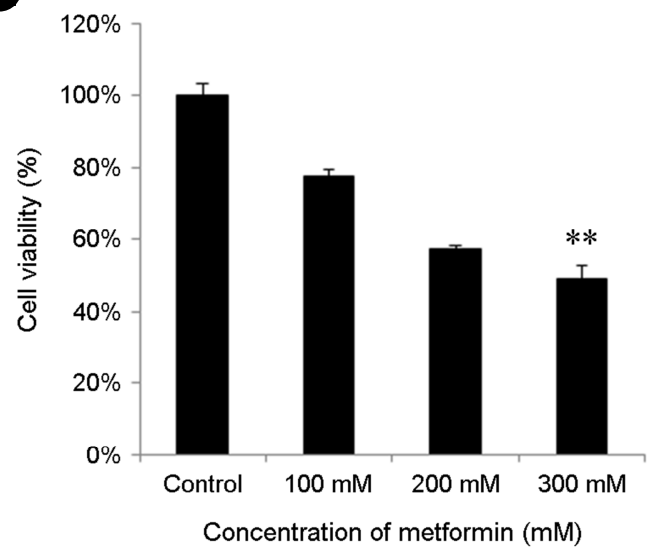

C

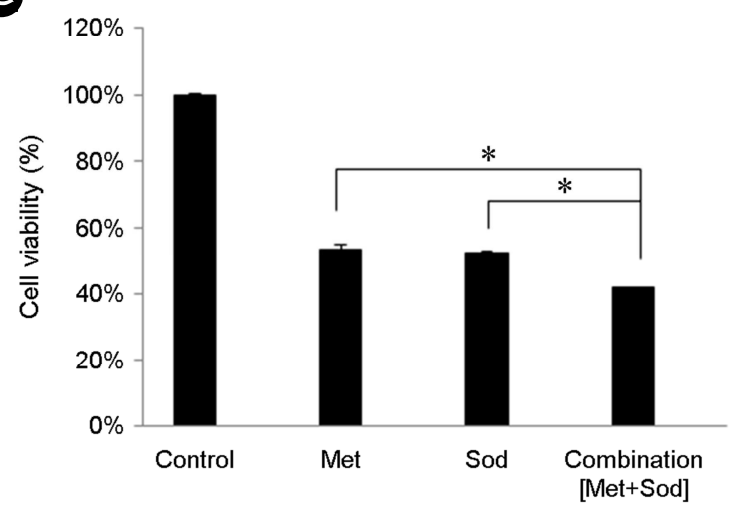

B

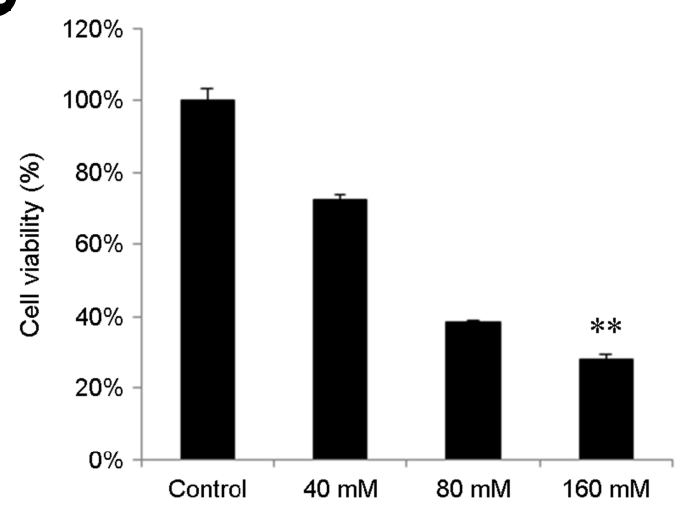

Concentration of sodium salicylate $(\mathrm{mM})$

D

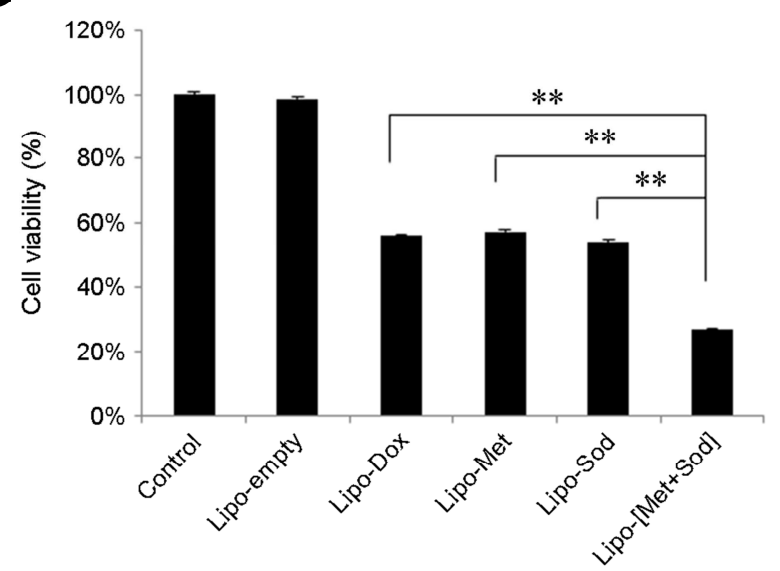

Fig. 3. Cytotoxicity of the dual drug-loaded liposomes in MCF-7 cells. The all control groups were treated with saline. (A and B) To evaluate of $\mathrm{IC}_{50}$ for each two-drug, MCF-7 cells were incubated with various concentration of metformin or sodium salicylate. Cell viavility was each monitored by WST assay method using EZ-CyTox reagents after $48 \mathrm{hrs}$. (C and D) To measure the cytotoxicity senergic effect of the dual drug-loaded liposomes, MCF-7 cells were treated with the combined the free dual drugs (combination) or the dual drug-loaded liposomes (Lipo-[Met+Sod]) for $48 \mathrm{hrs}$. Data are represented as the mean \pm standard deviation $(\mathrm{n}=3)$. A; $* * P<0.01$ compared with the control, B; $* * P<0.01$ compared with the control, $\mathrm{C}$; $* P<0.05$, compared with metformin or sodium salicylate respectively, $\mathrm{D}$; $* * P<0.01$ compared with Lipo-Dox, Lipo-Met or Lipo-Sod respectively. 
A

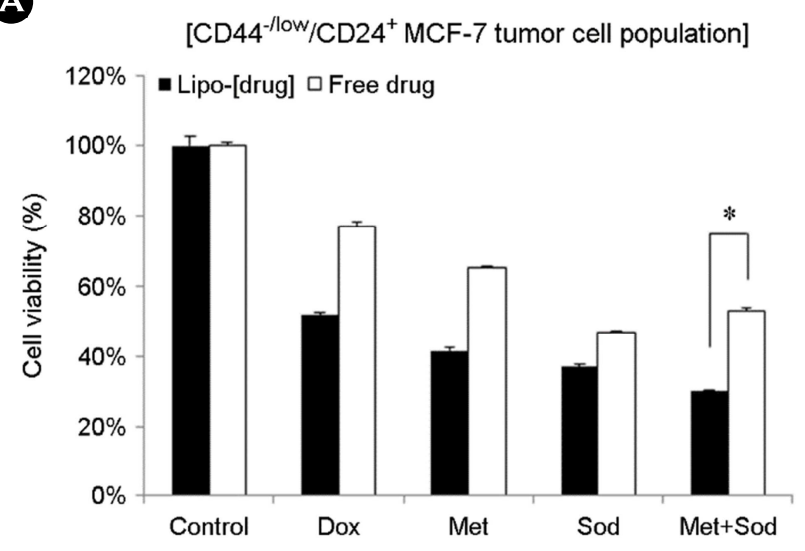

B

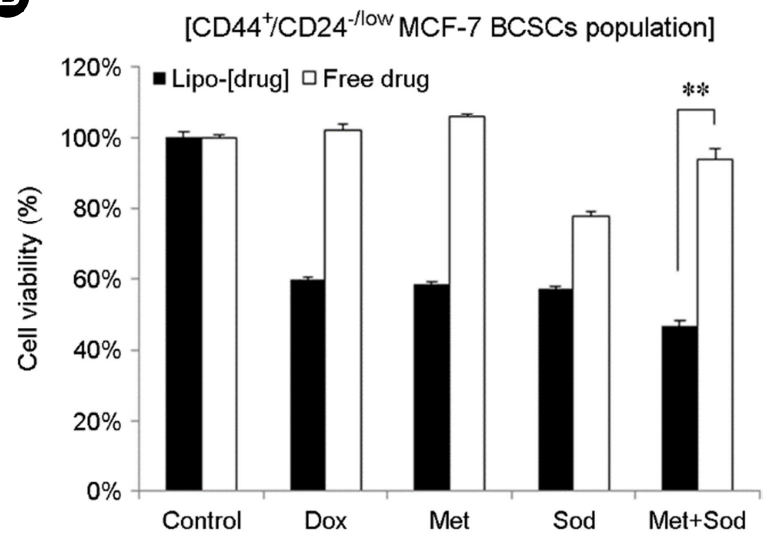

C

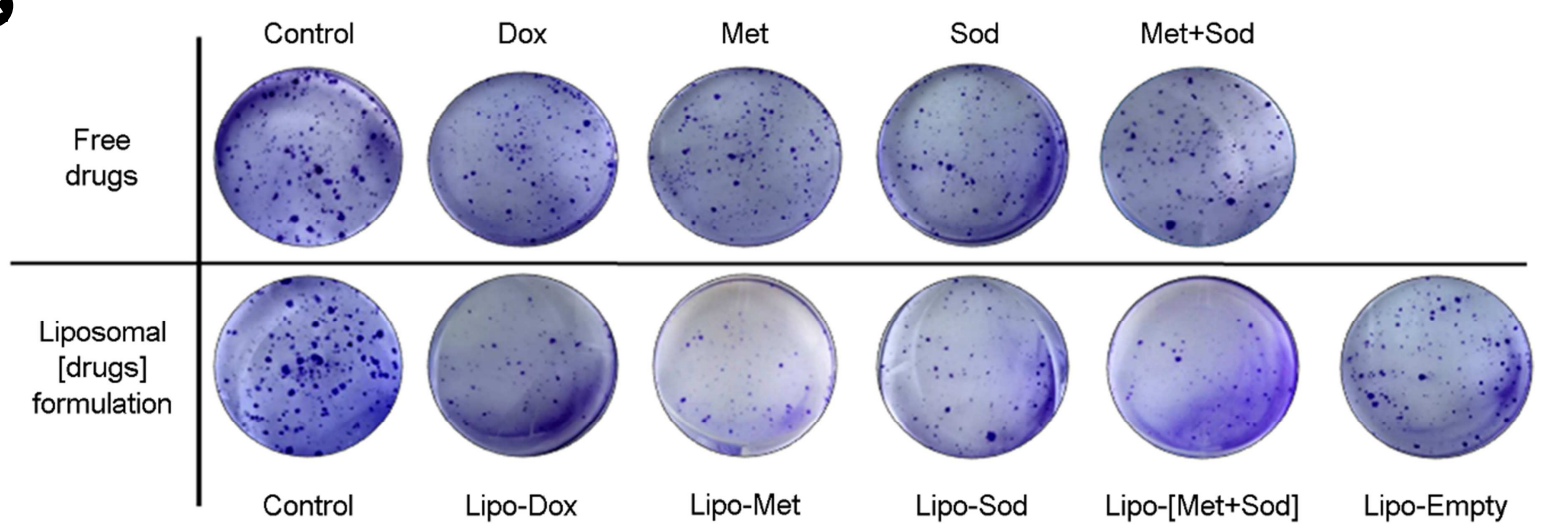

(D)

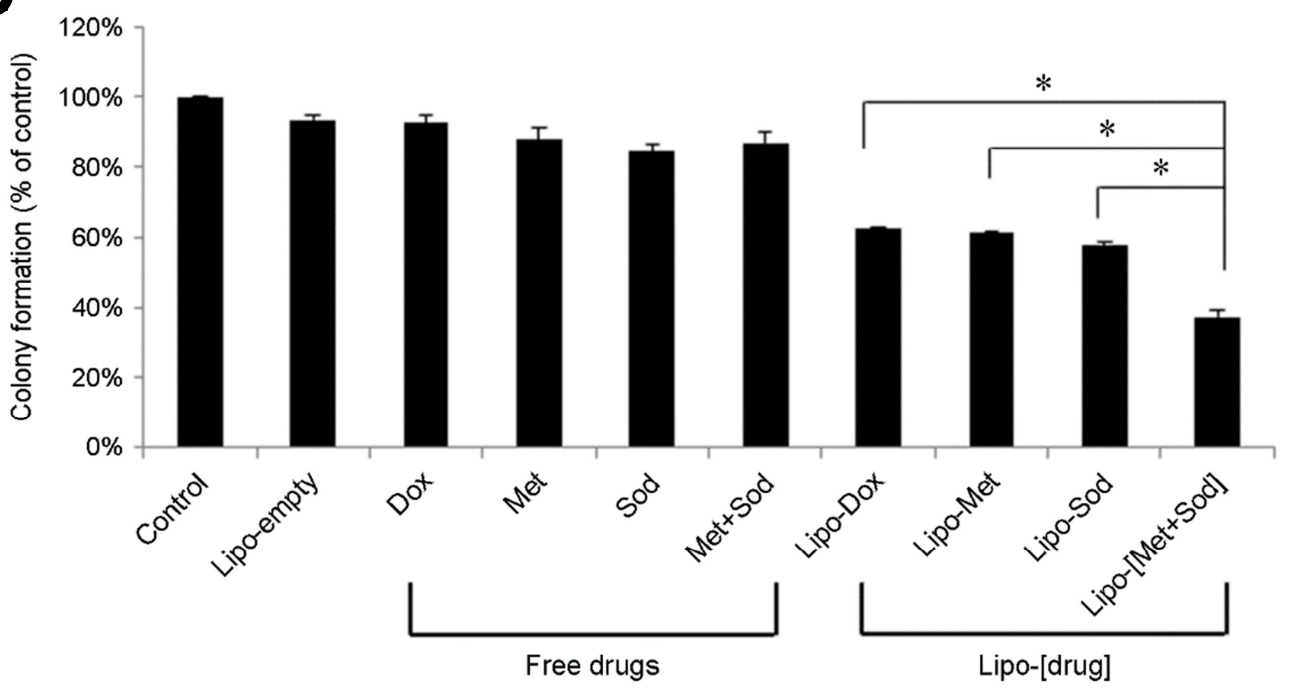

Fig. 4. Anti-proliferation effect of dual drug-loaded liposomes on BCSCs. The growth of the isolated CD $44^{- \text {-low }} / \mathrm{CD} 24^{+} \mathrm{MCF}-7$ tumor cells (A) and the isolated CD44 $/$ CD24-llow MCF-7 BCSCs (B) treated with free drugs (Dox, Met, Sod, and Met+Sod) or liposomal encapsulated drugs (Lipo-Dox, Lipo-Met, Lipo-Sod, and Lipo-[Met+Sod]) for 48 hours was determined by WST-1 assay. The data were caculated as percentage of contol (DPBS). The colonies formed in BCSCs-seeded 6-well plate after treatment of various free drugs or liposomal encapsulated drugs for 14 days were stained with crystal violet $(0.5 \% \mathrm{w} / \mathrm{v})$ and obserbved by a bright-field microscope (C) and quantfied (D). Data shown represent the mean \pm SD of three experiments $(* P<0.05, * * P<0.01)$. Abbreviations: BCSCs, breast cancer stem cells; DPBS, Dulbecco's phosphate buffered saline; Dox, doxorubicin; Met, metformin; Sod, sodium salicylate, Lipo-, liposomal encapsulated; SD, standard deviation. 
cells and BCSs.

\section{In vitro cytotoxicity of dual drug-loaded DMPG-POPC liposomes in MCF-7 cancer cells}

To compare the combination effect on cytotoxicity between free dual drugs (Met and Sod) and dual drug-loaded DMPG-POPC liposomes, we evaluated their efficacy in MCF-7 breast cancer cells in vitro. First, the cytotoxicity of the free drugs was compared with that of the combined free drugs. Combined free drugs [Met+Sod] $\left(\mathrm{IC}_{25}\right.$ of Met $(150 \mathrm{mM})$ and $\mathrm{IC}_{25}$ of Sod $(30 \mathrm{mM})$; Fig. 3C) exhibited approximately $15 \%$ increase $(P<0.05)$ in cell death relative to that of each free drug $\left(\mathrm{IC}_{50}\right.$ of Met $(300 \mathrm{mM})$ and $\mathrm{IC}_{50}$ of Sod (60 mM); Fig. 3A and B). Next, the cytotoxicity of dual drug-loaded DMPG-POPC liposomes, Lipo-[Met+Sod] $\left(\mathrm{IC}_{25}\right.$ of Met $(150 \mathrm{mM})$ and $\mathrm{IC}_{25}$ of Sod $\left.(30 \mathrm{mM})\right)$, was more cytotoxic than single drug-loaded liposomes (Fig. 3D). The results demonstrated that dual drug-loaded DMPG-POPC liposomes group (Lipo-[Met+Sod]) was taken up more into MCF-7 cells than free combined drugs, and they acted more efficiently to suppress cell proliferation that that of free drug group.

\section{In vitro evaluation of dual drug-loaded DMPG-POPC liposomes in MCF-7 BCSCs}

To evaluate the synergic effect against cell proliferation between single free drug (Met or Sod) and the dual drugloaded DMPG-POPC liposomes, we conducted the WST-1 assay in BCSCs. The isolated CD $44^{+} / \mathrm{CD} 24^{- \text {llow }} \mathrm{MCF}-7$ BCSC population and CD $44^{-/ l o w} / \mathrm{CD} 24^{+} \mathrm{MCF}-7$ tumor cell population were treated with the same concentrations of drugs (Fig. $3 \mathrm{C}$ and D). In the $\mathrm{CD} 44^{+} / \mathrm{CD} 24^{-/ \mathrm{low}}$ population, there was no difference in the cytotoxic effect among each free drug group (Fig. 4B). In contrast, compared with the combined free drug (Met+Sod)-treated BCSCs, dual drug [Met+Sod]-DMPG-POPC liposome-treated cells showed significant cell growth inhibition or cell death (Fig. 4B). However, a more growth-inhibitory effect was observed in BCSCs than in MCF-7 cells. Collectively, these data showed that the DMPG-POPC-based liposome delivery system displayed higher decrease in chemo-resistance and increase in sensitivity to anti-cancer therapy of BCSCs than free drugs.

\section{Colony formation assay}

Long-term cytotoxicity assaying on 14 days after the treat ment of free drugs (Met or/and Sod) or dual drug [Met+ Sod]-DMPG-POPC liposomes on BCSCs was analyzed using a colony formation assay. Fig. 4 (C and D) shows that the colony formation ability of Lipo-Empty (95\%) group or free drug (average 91\%) group was similar to that of the control (100\%) group. On the contrary, the rate of colony formation was diminished when BCSCs were treated with drug-loaded DMPG-POPC liposomes (Lipo-Dox, Met, and Sod). The Lipo-[Met+Sod] group was the most effective in decreasing colony formation to $36 \%(P<0.05)$.

\section{DISCUSSION}

In recent years, liposome-based drug delivery systems have gained remarkable interest, as they improve the efficacy of traditional therapeutics through controlled release, enhanced tumor accumulation, and reduced systemic toxicities (Allen and Cullis, 2013). However, a major problem in the current cancer therapy is drug resistance of metastatic cancers, resulting in 90\% drug failures (Longley and Johnston, 2005). This drug resistance is believed to be because CSCs are exposed to small amounts drugs, increasing the risk of recurrence of cancer, which rapidly grows and resists chemotherapy or radiotherapy (Vinogradov and Wei, 2012). Thus, it is important to develop a novel platform that overcomes drug resistance and accumulates anti-cancer drugs at the tumor site.

In this study, we designed two liposomal formulations, DMPG-POPC- and CHOL-POPC-based liposomes, to choose a liposomal formulation that can increase their uptake by target cells effectively. Negatively charged DMPG tends to inhibit aggregation and enhances liposome stability in suspension during storage, preventing the leakage of reagents from the liposomal formulation compared with that by positively or neutrally charged liposomes (Alhariri et al., 2017). Therefore, in our design, the liposomes were selected owing to their advantage of possessing negatively charged DMPG lipid. Our results demonstrated that DMPG-POPC-based liposomes have improved cellular-binding efficacy in vitro 
compared with that of the CHOL-POPC-based liposomes in MCF-7 cells in a time-dependent manner (Fig. 2). Furthermore, with DMPG-POPC liposomes, we could increase the loading of two drugs with relatively higher efficiency to increase the effectiveness of liposomal nanoparticles reaching the tumor site.

The cytotoxicity assay revealed that dual drug-loaded DMPG-POPC liposomes (Lipo-[Met+Sod]) is an effective means to deliver Met and Sod to MCF-7 breast cancer cells at their optimal synergistic ratio $\left(\mathrm{IC}_{25}\right.$ of Met $(150 \mathrm{mM})+$ $\mathrm{IC}_{25}$ of Sod (30 mM )) for improved therapeutic effect. Our results demonstrated that Lipo-[Met+Sod] had improved efficacy in vitro compared with that of the free drug combination (Fig. 3). Furthermore, MCF-7 cells treated with DMPG-POPC liposomes demonstrated higher cytotoxicity rate than that of cells treated with CHOL-POPC liposomes (data not shown). These results of the cell viability assay suggest that DMPG-POPC liposomes enhance the interaction with membranes of MCF-7 cells and accumulate a high amount of drugs into cells.

Although its application for BCSC-targeted therapy shows a limited therapeutic efficacy, Met has been proven to be an effective drug against breast cancer in an animal study (Han and Crowe, 2009). To improve the inhibitory capacity of Met against BCSCs, in this study, for the first time, we demonstrated the synergy between Met and Sod and their incorporation into DMPG-POPC-based liposomes for improved therapeutic effect. The cell viability assay in BCSCs revealed that $\mathrm{CD} 44^{+} / \mathrm{CD} 24^{- \text {-low }} \mathrm{MCF}-7$ population treated with free Met and Sod had no cytotoxic effect (Fig. 4B). This result suggested that $\mathrm{CD} 44^{+} / \mathrm{CD} 24^{- \text {-low }}$ populations (BCSCs) had a property of drug resistance. However, $\mathrm{CD} 44^{+} / \mathrm{CD} 24^{- \text {-low }}$ MCF-7-treated with the dual drug-loaded DMPG-POPC liposomes showed enhanced growth-inhibitory effect in both short-term cytotoxicity assay on 24 hours by anti-proliferation assay (Fig. 4B) and long-term cytotoxicity assay on 14 days by a colony formation assay (Fig. 4C and D). This could be attributed to the high affinity of DMPG-based liposomes to BCSCs, enhancing the intracellular accumulation of Met and Sod and mediating endocytosis.

This delivery system enhanced the delivery of Met and Sod to breast cancer cells and BCSCs compared with that of these free drugs alone, thus promoting effective regression of both cancer cells and BCSCs. On the basis of these results, by combining the enhanced drug delivery capability of DMPG-POPC liposomes with successful combination therapies, significant advances in medicine could be made with propound positive effect in clinical settings. Furthermore, the DMPG-POPC liposome delivery system can minimize the disadvantages of Met and Sod that restrict their effective applications in vivo, such as poor solubility, off-target effects, instability, short circulation half-life, undesirable biodistribution, and low therapeutic indices. Overall, our results suggest that the negative charge-based DMPG-POPC liposomal formulation has a high potential to be used as a promising delivery system for dual drug (Metformin and sodium salicylate) treatment in breast cancer therapy.

\section{ACKNOWLEDGEMENT}

This research was supported by Basic Science Research Program through the National Research Foundation of Korea (NRF) funded by the Ministry of Education (NRF-2018R1D1A1B07045861).

\section{CONFLICT OF INTEREST}

The authors have no conflict of interest to declare.

\section{REFERENCES}

Alhariri M, Majrashi MA, Bahkali AH, Almajed FS, Azghani AO, Khiyami MA, Alyamani EJ, Aljohani SM, Halwani MA. Efficacy of neutral and negatively charged liposome-loaded gentamicin on planktonic bacteria and biofilm communities. Int J Nanomedicine. 2017. 12: 6949-6961.

Alimova IN, Liu B, Fan Z, Edgerton SM, Dillon T, Lind SE, Thor AD. Metformin inhibits breast cancer cell growth, colony formation and induces cell cycle arrest in vitro. Cell Cycle. 2009. 8: 909-915.

Allen TM, Cullis PR. Liposomal drug delivery systems: From concept to clinical applications. Adv Drug Deliv Rev. 2013. 65: 36-48.

Amann R, Peskar BA. Anti-inflammatory effects of aspirin and sodium salicylate. Eur J Pharmacol. 2002. 447: 1-9.

Bao B, Wang Z, Ali S, Ahmad A, Azmi AS, Sarkar SH, Banerjee S, Kong D, Li Y, Thakur S, Sarkar FH. Metformin inhibits cell 
proliferation, migration and invasion by attenuating csc function mediated by deregulating mirnas in pancreatic cancer cells. Cancer Prev Res. 2012. 5: 355-364.

Bellosillo B, Pique M, Barragan M, Castano E, Villamor N, Colomer D, Montserrat E, Pons G, Gil J. Aspirin and salicylate induce apoptosis and activation of caspases in b-cell chronic lymphocytic leukemia cells. Blood. 1998. 92: 1406-1414.

Bowker SL, Majumdar SR, Veugelers P, Johnson JA. Increased cancer-related mortality for patients with type 2 diabetes who use sulfonylureas or insulin. Diabetes Care. 2006. 29: 254-258.

De Jong WH, Borm PJA. Drug delivery and nanoparticles: Applications and hazards. International Journal of Nanomedicine. 2008. 3: 133-149.

Dean M, Fojo T, Bates S. Tumour stem cells and drug resistance. Nat Rev Cancer. 2005. 5: 275-284.

Dikshit P, Chatterjee M, Goswami A, Mishra A, Jana NR. Aspirin induces apoptosis through the inhibition of proteasome function. J Biol Chem. 2006. 281: 29228-29235.

Dowling RJ, Zakikhani M, Fantus IG, Pollak M, Sonenberg N. Metformin inhibits mammalian target of rapamycin-dependent translation initiation in breast cancer cells. Cancer Res. 2007. 67: 10804-10812.

Evans JM, Donnelly LA, Emslie-Smith AM, Alessi DR, Morris $\mathrm{AD}$. Metformin and reduced risk of cancer in diabetic patients. Bmj. 2005. 330: 1304-1305.

Flossmann E, Rothwell PM. Effect of aspirin on long-term risk of colorectal cancer: Consistent evidence from randomised and observational studies. Lancet. 2007. 369: 1603-1613.

Gangemi R, Paleari L, Orengo AM, Cesario A, Chessa L, Ferrini S, Russo P. Cancer stem cells: A new paradigm for understanding tumor growth and progression and drug resistance. Curr Med Chem. 2009. 16: 1688-1703.

Han JS, Crowe DL. Tumor initiating cancer stem cells from human breast cancer cell lines. Int J Oncol. 2009. 34: 1449-1453.

Hirsch HA, Iliopoulos D, Struhl K. Metformin inhibits the inflammatory response associated with cellular transformation and cancer stem cell growth. Proc Natl Acad Sci U S A. 2013. 110: 972-977.

Jeong K, Kang CS, Kim Y, Lee YD, Kwon IC, Kim S. Development of highly efficient nanocarrier-mediated delivery approaches for cancer therapy. Cancer Lett. 2016. 374: 31-43.

Ji P, Zhang Y, Wang SJ, Ge HL, Zhao GP, Xu YC, Wang Y. Cd44hicd24lo mammosphere-forming cells from primary breast cancer display resistance to multiple chemotherapeutic drugs. Oncol Rep. 2016. 35: 3293-3302.
Jiralerspong S, Palla SL, Giordano SH, Meric-Bernstam F, Liedtke C, Barnett CM, Hsu L, Hung MC, Hortobagyi GN, GonzalezAngulo AM. Metformin and pathologic complete responses to neoadjuvant chemotherapy in diabetic patients with breast cancer. J Clin Oncol. 2009. 27: 3297-3302.

Lee EJ. Cancer chemoprevention effects of geldanamycin and 17aag in human oral squamous cell carcinoma. Korean Journal of Clinical Laboratory Science. 2018. 50: 462-469.

Kai M, Kanaya N, Wu SV, Mendez C, Nguyen D, Luu T, Chen S. Targeting breast cancer stem cells in triple-negative breast cancer using a combination of lbh589 and salinomycin. Breast Cancer Res Treat. 2015. 151: 281-294.

Kim J-E, Kang B-I, Bae S-M, Han S, Jun A, Han J, Cho M-A, Choi Y-L, Lee J-H, Moon Y-H. An analytical validation of the geneswell tm bct multigene prognostic test in patients with early breast cancer. Korean Journal of Clinical Laboratory Science. 2017a. 49: 79-87.

Kim Y-J, Park H-B, Kim P-H, Park JS, Kim K-S. Enhanced anticancer efficacy in mcf-7 breast cancer cells by combined drugs of metformin and sodium salicylate. Biomedical Science Letters. 2017b. 23: 290-294.

Klampfer L, Cammenga J, Wisniewski H-G, Nimer S. Sodium salicylate activates caspases and induces apoptosis of myeloid leukemia cell lines. Blood. 1999. 93: 2386-2394.

Law BK, Waltner-Law ME, Entingh AJ, Chytil A, Aakre ME, Norgaard P, Moses HL. Salicylate-induced growth arrest is associated with inhibition of p70s6k and down-regulation of c-myc, cyclin d1, cyclin a, and proliferating cell nuclear antigen. J Biol Chem. 2000. 275: 38261-38267.

Li X, Lewis MT, Huang J, Gutierrez C, Osborne CK, Wu MF, Hilsenbeck SG, Pavlick A, Zhang X, Chamness GC, Wong H, Rosen J, Chang JC. Intrinsic resistance of tumorigenic breast cancer cells to chemotherapy. J Natl Cancer Inst. 2008. 100: 672-679.

Libby G, Donnelly LA, Donnan PT, Alessi DR, Morris AD, Evans $\mathrm{JM}$. New users of metformin are at low risk of incident cancer: A cohort study among people with type 2 diabetes. Diabetes Care. 2009. 32: 1620-1625.

Liu B, Fan Z, Edgerton SM, Deng XS, Alimova IN, Lind SE, Thor AD. Metformin induces unique biological and molecular responses in triple negative breast cancer cells. Cell Cycle. 2009. 8: 2031-2040.

Longley DB, Johnston PG. Molecular mechanisms of drug resistance. J Pathol. 2005. 205: 275-292.

Minn AJ, Kang Y, Serganova I, Gupta GP, Giri DD, Doubrovin M, 
Ponomarev V, Gerald WL, Blasberg R, Massague J. Distinct organ-specific metastatic potential of individual breast cancer cells and primary tumors. J Clin Invest. 2005. 115: 44-55.

Mukherjee S, Mazumdar M, Chakraborty S, Manna A, Saha S, Khan P, Bhattacharjee P, Guha D, Adhikary A, Mukhjerjee S, Das T. Curcumin inhibits breast cancer stem cell migration by amplifying the e-cadherin/beta-catenin negative feedback loop. Stem Cell Res Ther. 2014. 5:116.

Nag O, Yadav V, Hedrick A, Awasthi V. Post-modification of preformed liposomes with novel non-phospholipid poly(ethylene glycol)-conjugated hexadecylcarbamoylmethyl hexadecanoic acid for enhanced circulation persistence in vivo. International Journal of Pharmaceutics. 2013. 446: 119-129.

Song X, Ren Y, Zhang J, Wang G, Han X, Zheng W, Zhen L. Targeted delivery of doxorubicin to breast cancer cells by aptamer functionalized dotap/dope liposomes. Oncol Rep. 2015. 34: 1953-1960.

Ulrich CM, Bigler J, Potter JD. Non-steroidal anti-inflammatory drugs for cancer prevention: Promise, perils and pharmacogenetics. Nat Rev Cancer. 2006. 6: 130-140.
Vinogradov S, Wei X. Cancer stem cells and drug resistance: The potential of nanomedicine. Nanomedicine. 2012. 7: 597-615.

Zakikhani M, Dowling RJ, Sonenberg N, Pollak MN. The effects of adiponectin and metformin on prostate and colon neoplasia involve activation of amp-activated protein kinase. Cancer Prev Res. 2008. 1: 369-375.

Zhang Z, Ni C, Chen W, Wu P, Wang Z, Yin J, Huang J, Qiu F. Expression of cxcr4 and breast cancer prognosis: A systematic review and meta-analysis. BMC Cancer. 2014. 14: 1471-2407.

Zou Y, Priebe W, Perez-Soler R. Lyophilized preliposomal formulation of the non-cross-resistant anthracycline annamycin: Effect of surfactant on liposome formation, stability and size. Cancer Chemother Pharmacol. 1996. 39: 103-108.

https://doi.org/10.15616/BSL.2019.25.2.159

Cite this article as: Park HB, Kim YJ, Lee SM, Park JS, Kim KS. Dual Drug-Loaded Liposomes for Synergistic Efficacy in MCF-7 Breast Cancer Cells and Cancer Stem Cells. Biomedical Science Letters. 2019. 25: 159-169. 